\title{
إشكاليات الخطاب الإسلامي المعاصر
}

عبد الكريه رباح مقداد

دكتوراه في الفقه المقارن

جامعة الزيتونة- فلسطين
رفيق أسعد رضوان

أستاذ الفقه المقارن المساعد

الجامعة الإسلامية بغزة- فلسطين

rradwan@iugaza.edu.ps 


\title{
إشكاليات الخطاب الإسلامي المعاصر
}

\author{
رفيق أسعد رضوان \\ أستاذ الفقه المقارن المساعد- الجامعة الإسلامية بغزة- فلسطين \\ rradwan@iugaza.edu.ps \\ عبد الكريم رباح مقداد \\ دكتوراه في الفقه المقارن- جامعة الزيتونة - فلسطين مقداد
}

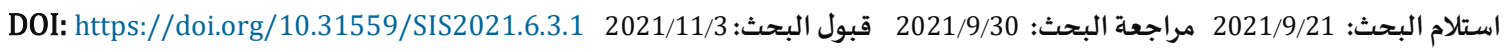

الشريعة الإسلامية هي خاتمة الرسالات وهي صالحة لكل زمان ومكان، وهي قادرة على أن تجيب وتبين أحكام كل مسألة

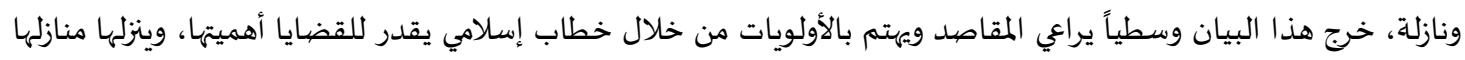

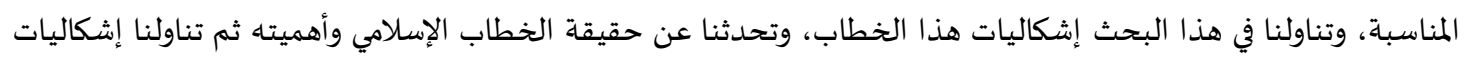
الفقه الإسلامي المعاصر، وختمنا بخاتمة فيها أهم النتائج والتوصيات. الكلمات المفتاحية: الخطاب؛ الإسلامي؛ الأولوية؛ الإشكاليات؛ المعاصر.

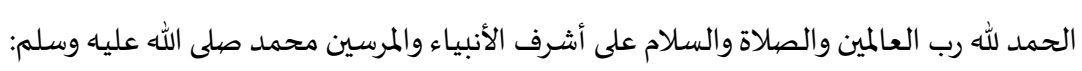

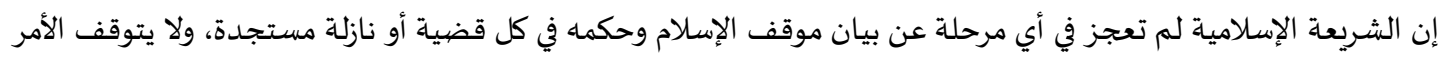

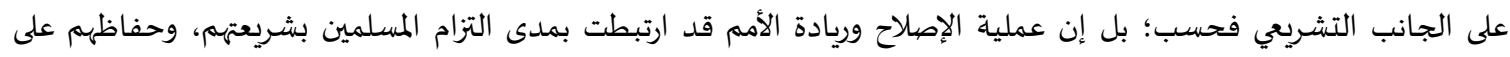

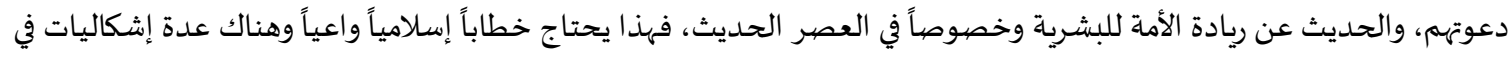

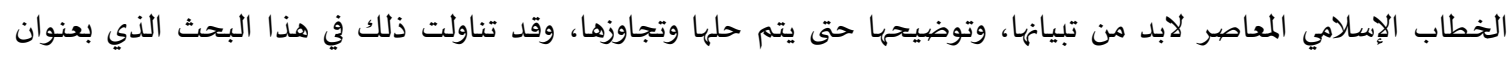

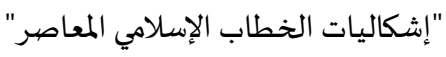

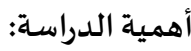
1. تسليط الضوء على الإشكاليات في الخطاب الإسلامي المعاصر وبيانها يعد أول خطوات الحلح والحكمة على الشيء فرع عن تصوروه.

$$
\text { 2. }
$$
3.

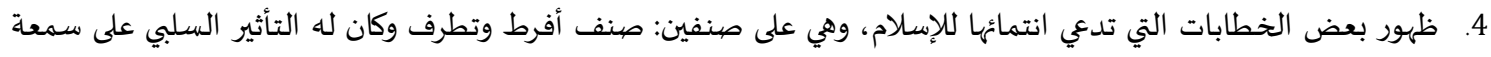

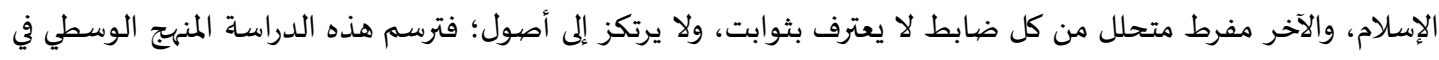


الدراسات السـابقة:

لم أجد دراسة علمية تطرقت إلى الموضوع بشكل خاص وإن كان هناك مقالات منشورة لم تصل لدرجة الأبحاث أو الدراسات،

$$
\begin{aligned}
& \text { وهناك جملة من المؤلفات التي تناولت الخطاب الإسلامي بشكل عام، بطروف وأهمها: }
\end{aligned}
$$

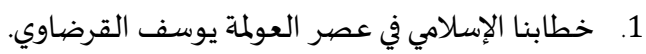

$$
\begin{aligned}
& \text { 2. الخطاب الإسلامي والقضايا المعاصرة د حسن السيد عز الدين بحر العلوم. } \\
& \text { 3. بحث الخطاب الإسلامي المعاصر: نماذج تحليلياية: محمد مراح. } \\
& \text { 4. بحث تجديد الخطاب الإسلامي بين الأصالة والمعاصرة عبد الله عبد ربهاه. }
\end{aligned}
$$

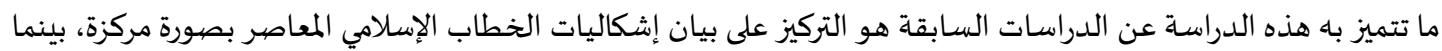

$$
\text { الأخرى تناولت الخطاب بشكل عام وتجديده، بعيداً عن الحديث عن الإشكاليات. }
$$

$$
\text { منهجج الدراسـة: }
$$

المنهج المتبع في هذا البحث المنهج الوصفي التحليلي؛ لأنها المنهج الملائم لطبيعة البحث وموضوعاه؛ حيث جمعت المادة العلمية من مظاها، وهي مراجع الفقه، وكتب التفسير، وشروح الحديث، والكتب المعاصرة، ووصفها وتحليلها؛ مؤصلاً للوصول إلى النتائج والتوصيات.

حدود الدراسـة: يسعى هذا البحث إلى رسم إشكاليات الخطاب الإسلامي المعاصر بصورة شاملة كاملة، من هنا فإن الباحثين التزماً بجمع المادة

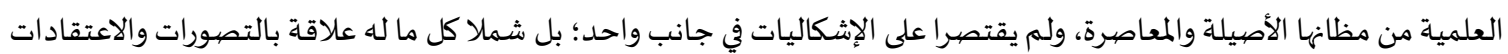

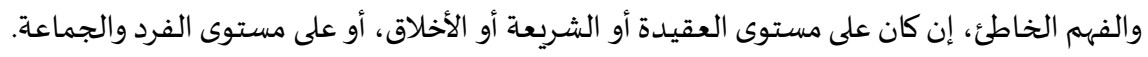

خطة الداسـة:

وتشتمل على مقدمة ومبحثين وخاتمة:

المبحث الأول: حقيقة الخطاب الإسلامي وأهميته.

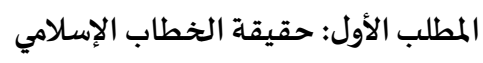

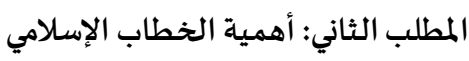

المبحث الثاني: إشكاليات الخطاب الإسلامي المعاصئ الخطاب الإهي

\section{المبحث الأول: حقيقة الخطاب الإسلامي وأهميته:}

يعتبر مصطلح الخطاب من أكثر المصطلحات المعاصرة استعمالاً، وقد ارتبط بمعظم العلوم والفنون، حتى ذهب البعض إلى فئل

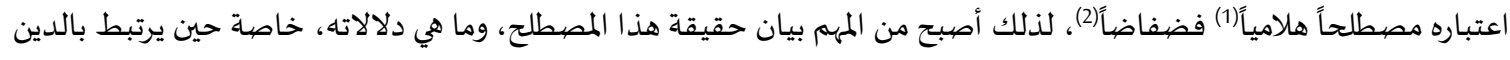
الإسلامي، ولابد كذلك من الإشارة إلى أهمية الخطاب الإسلامي؛ وذلك لوضعاه في نصابه الصحيح، وتنزيله منزلته الحقيقية.

المطلب الأول: حقيقة الخطاب الإسلامي:

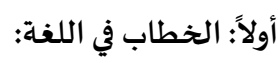

قال ابن فارس: "الخاء والطاء والباء أصلان, ويطلق عند أهل اللغة على معنيين"(3):

الأول: الكلام بين اثنين، يقال خاطبه يخاطبه مخاطبة، ويطلق الخطب على الأمر الذي يقع صغيراً كان أم عظيماً (4)، ويطلق على

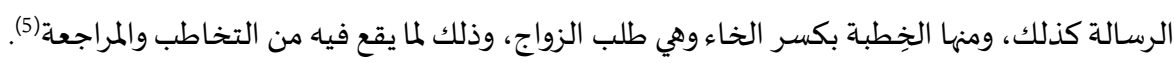

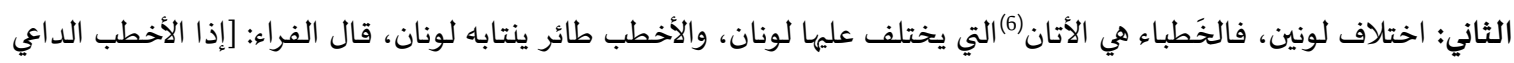
على الدوح صَرْصراً] (7).

1 مادة بروتينية شفافة تستخرج من الأنسجة الحيوانية المُخْتَفَة, مجمع اللغة العربية: المعجم الوسيط(992/2).

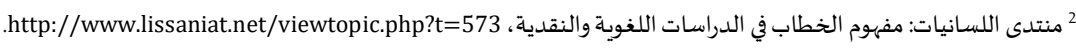
33 ابن فارس: مقاييس اللغة (198/2).

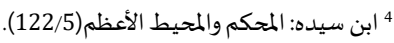

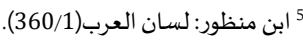
6 وهي أنثى الحمار ، ابن منظور: لسان العربان العرب(362/1).

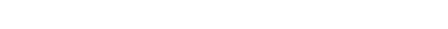


والمعنى الأول هو المراد، ويظهرمنه اقتصارمفهوم الخطاب في اللغة على المنطوق أو المكتوب. ثانياً: الخطاب عند المفسرين:

ذكر الله تعالى في كتابه العزيز؛ لفظة الخطاب ومشتقاتها في أكثر من موضع (8)، ولقد تناولها المفسرون بالتأويل، واختلفت

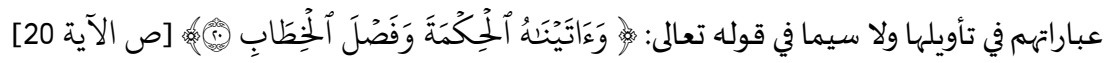

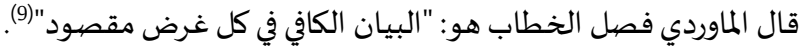

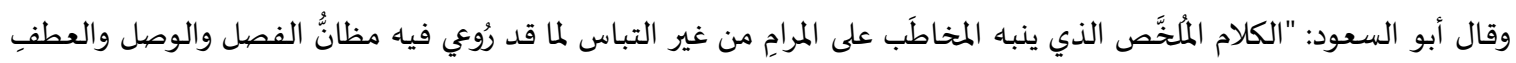
والاستئنافِ والإظهارِ والإضِمارِ والحذفِ والتِّكرارِ" (10).

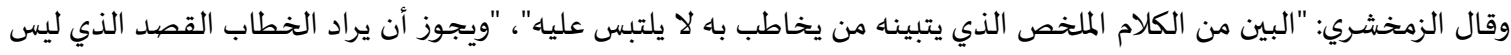
فيه اختصار مخلّ ولا إشباع مملّ"(11). وذهب الألوسي إلى ان فصل الخطاب هو: "فصل الخصام بتمييز الحق عن الباطل فالفصل بمعناه المصدري والخطاب الخصام

لاشتماله عليه أو لأنه أحد أنواعه خص بأل فاء لأنه المحتاج للفصل أو الككلام الذي يفصل بين الصحيح والفاسد، والحق والباطل" (12). يظهرللباحث أن الخطاب عند المفسرين لابد أن يتميز بـ:

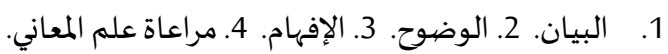
ثالثاً: الخطاب عند الأصهوليين:

اختلفت عبارات الأصوليين في تعريفهم للخطاب, وإن كانت جميع التعريفات تدور حول مفهوم واحد، وهو كما عرفه الآمدي:

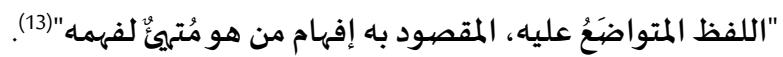

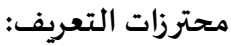
"اللفظ" احتراز عما وقعت المواضعة عليه من الحركات والإشارات المفهمة. "المتواضع عليه" احتراز عن الألفاظ المهملة.

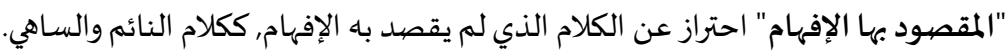

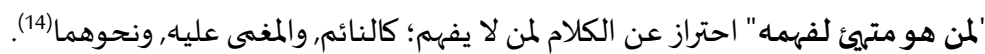
ولذلك كانت فائدة الخطاب هي إفهام المخاطَب (15). وقد اخترت تعريف الآمدي؛ لسلامته من الاعتراضات عند الأصهوليين، وشهرته من بين التعريفات الأخرى. وللخطاب عند الأصهوليين مفهوم وهو ما يعرف ب"مفهوم الخطاب" (16)، وهو على ثلاثة أوجاء:

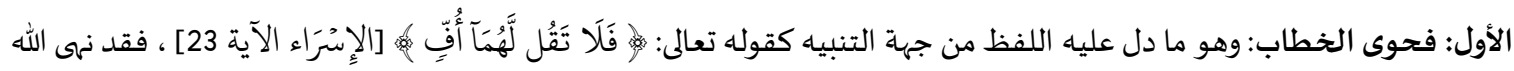

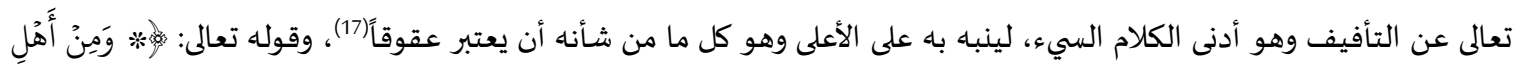

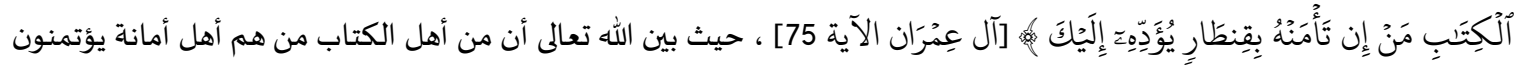

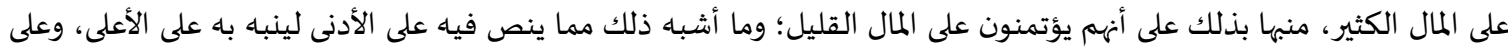
الأعلى لينبه باه على الأدنى (18).

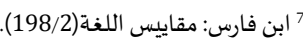

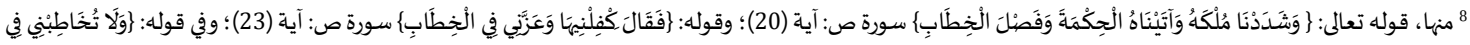

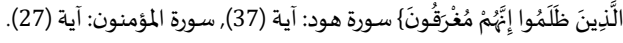

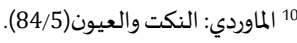

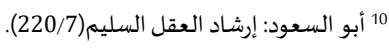
11 الزمخشري: الكشاف(10/80/4).

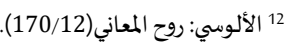

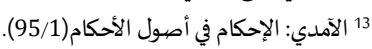

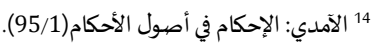

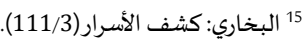

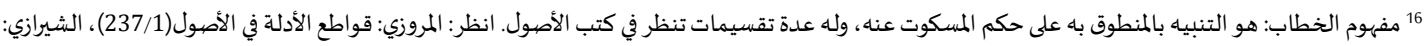

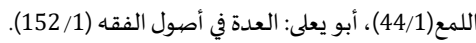

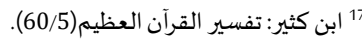
18 القرافي: شرح تنقيح الفصول(278/1)، الإسنوي: نهاية السول(149/1)، آنسير آل تيمية: المسودة(347/1). 
الثاني: لَحْنُ الخطاب، أو دلالة الاقتضياء: وهو ما دلَّ عليه اللفظ من الضمير، الذي لا يتم الكلام إلا به، وذلك مثل قوله تعالى: وهو

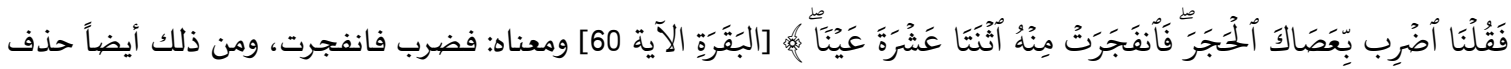

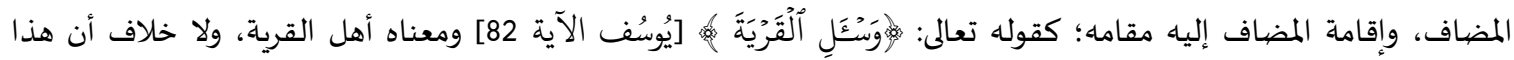
كالمنطوق به في الإفادة والبيان؛ ولا يجوز أن يضمر في مثل هذا إلا ما تدعو الحاجة المانة إليه (19).

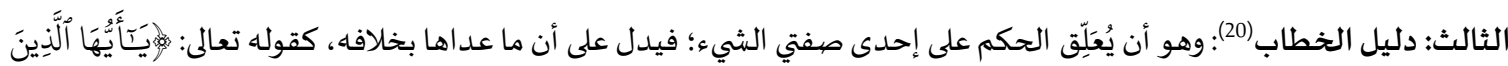

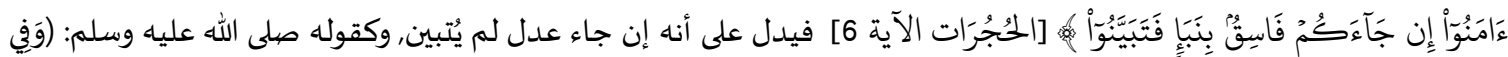

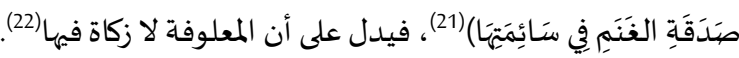

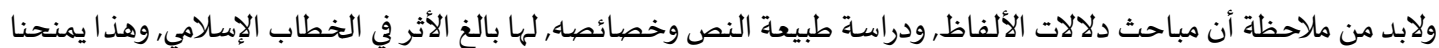
الكثير من الدقة والمرونة في الوقت نفسه لإعادة صياغة الخطاب الإناب الإسلامي المعاصر (23).

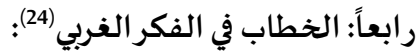

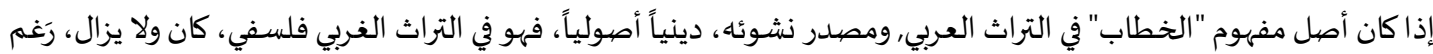

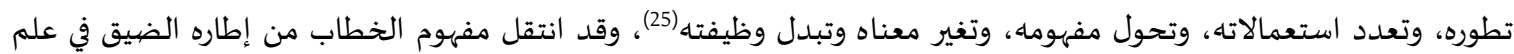

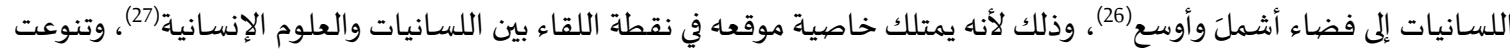

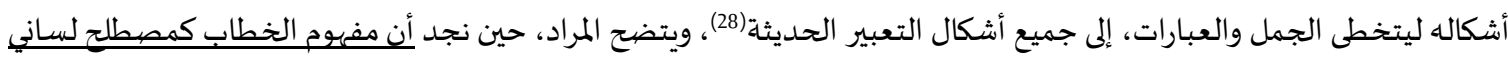
كان يعبر عن المنطوق فقط فهو:

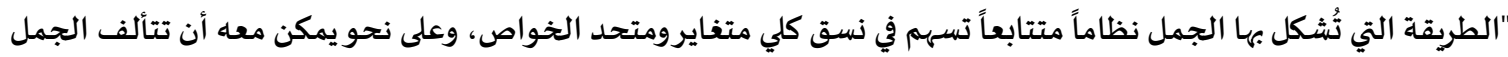

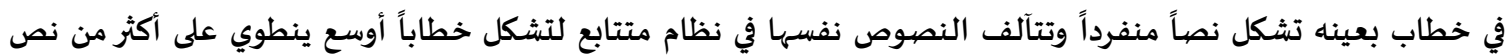
مفرد" (29). ومع تطور المصطلح، واعتباره مصططلحاً سيمائيا(30)؛ أصبيح يُعرَّف في الأدب المعاصر؛؛ بأنه:

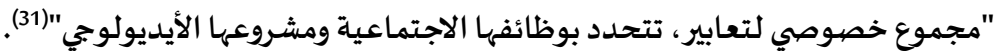

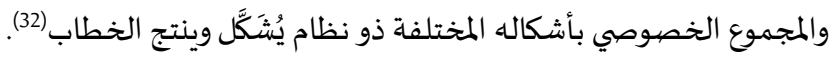

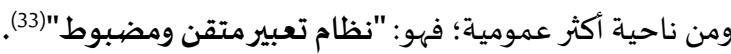

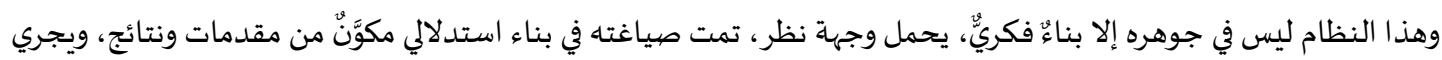

بين مرسِل ومستقبِل وفق عملية اتصال (34).

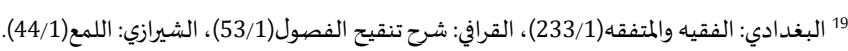

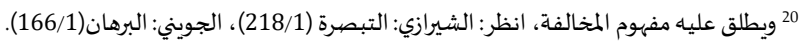

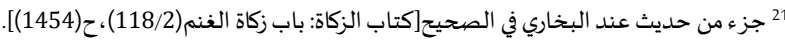

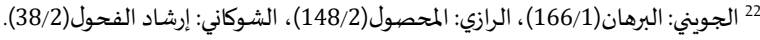

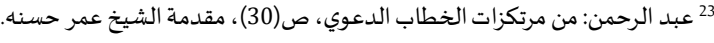

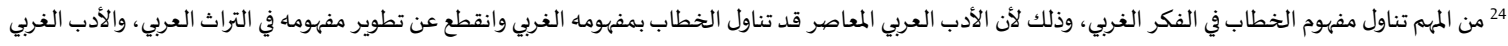

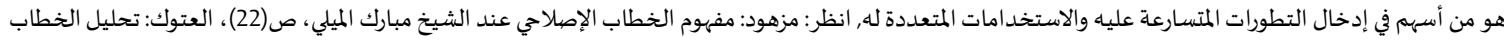

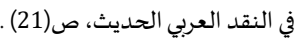

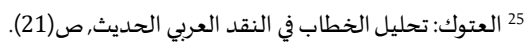

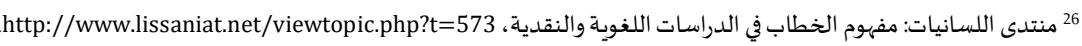

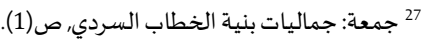

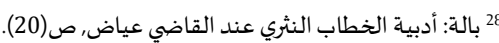
29 Literature-Forum--30 والسيمياء: هي دراسة جميع السلوكيات والأنظمة التواصلية، بحيث يدخل فهها اللغات والإشارات واللوحات والأصوات ولغة الأجساد، انظر: سلامة: سيميائية التحولات النصية,ص(71).

31 علوش: معجم المصطظحات الأدبية المعاصرة, ص(83) .

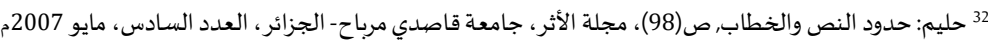

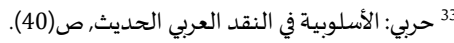
34 بالة: أدبية الخطاب النثري عند القاضي عياض, ص(19). 
خامساً: الخطاب في الفكر الإسلامي المعاصر:

يمثل الخطاب الإسلامي امتداداً طبيعياً لمفهوم الخطاب في ظل التطورات التي خضع لها، إلا أن ربطه بالدين أو أو بالأيديولوجيا، جعله أكثر وضوحاً، وهاؤم بعضاً من تلكم التعريفات:

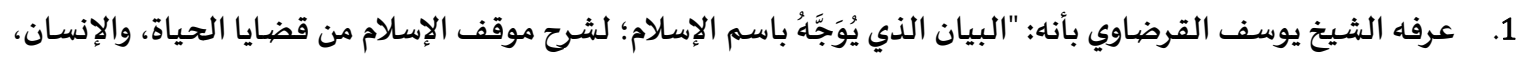
والعالم، فردية أو اجتماعية، روحية أو مادية، نظرية أو عملية" (35).

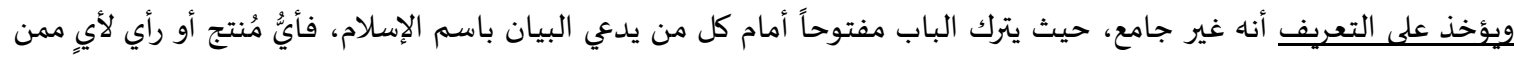

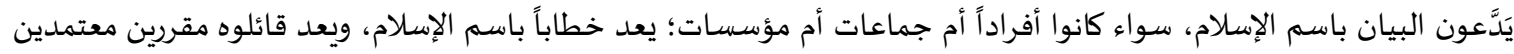

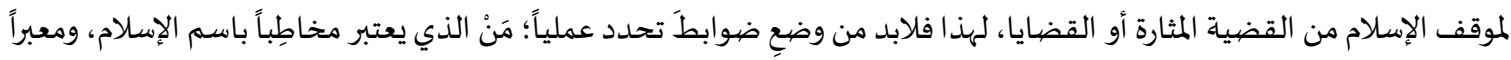
عن وجهة نظره الحقيقية.

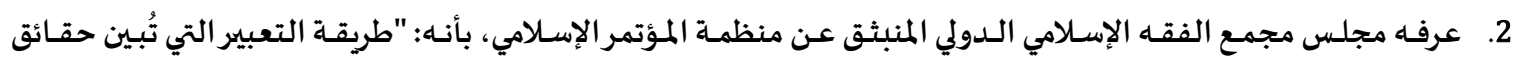

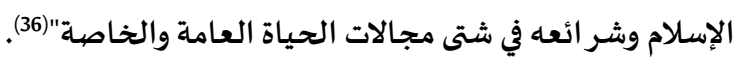

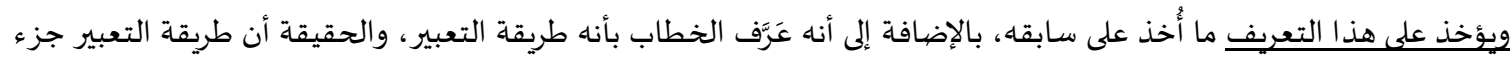

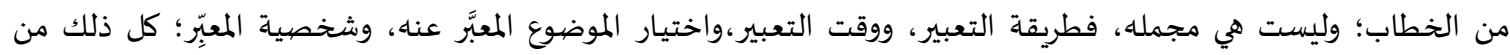
الخطاب. وعَرَّفه وسام فؤاد بأنه: "الخطاب الذي يستند لمرجعية إسلامية من أصول القرآن والسنة، وأيٍّ من سائر الفروع الإسلامية

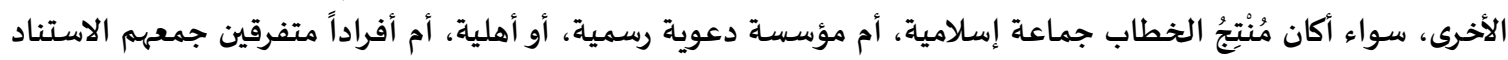

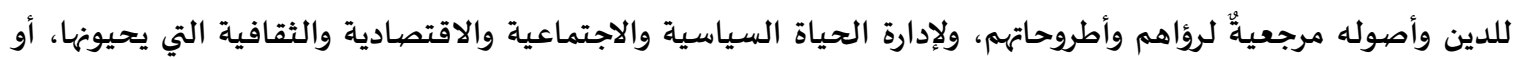

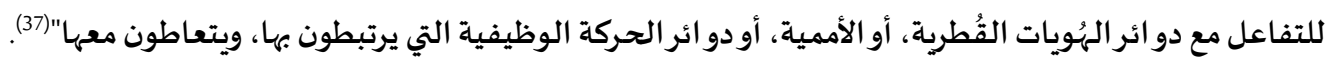

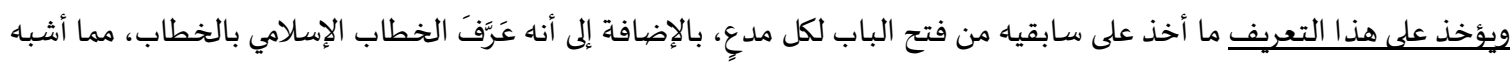

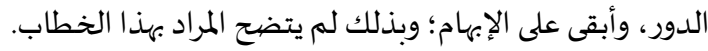
وبعد عرض التعريفات الثلاثة السابقة للخطاب الإسلامي، وبيان المآخذ أو الاعتراضات عليها، فيمكن للباحثين تعريف الخطاب الإسلامي بأنه:

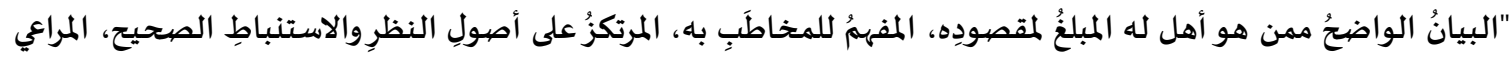

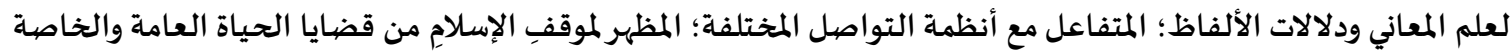
للمسلمين وغيرهم". • 1. تحديده لهوية ومقومات الخطاب الإسلامي، من حيث ارتكازه على أصول النظر والاستنباط الصحيح. 2. مراعاته لبعض العلوم المهمة التي يجب أن يشتمل عليها الخطاب الإسلامي ويستفيد منها، كعلم المعاني ودلالات الألاتلفاظ.

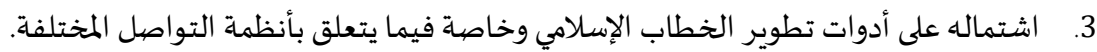

$$
\text { شرح التعريف وبيان محترزاته: }
$$

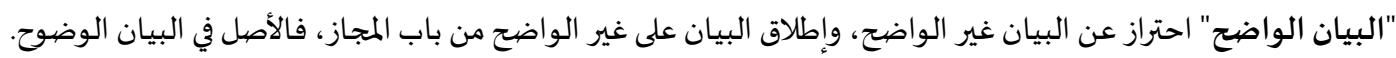

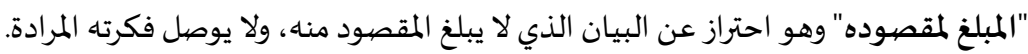

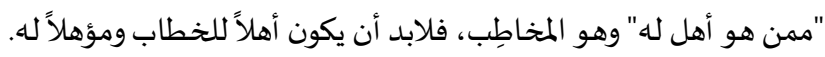
"المفهم للمخاطب به" وهو احتراز عن البيان غير المفهم للمخاطب باه، كالرموز المتعارف عليها بين أصحاب الفكر الواحد أو الدين الواحد. "المرتكزعلى أصهول النظروالاستنباط الصحيح" وبذلك يخرج البيان الذي لا يستند إلى أصول، ولا يبنى على قواعد شرعية صحيحة.

35 القرضاوي: خطابنا الإسلامي في عصر العولمة، ص(15).

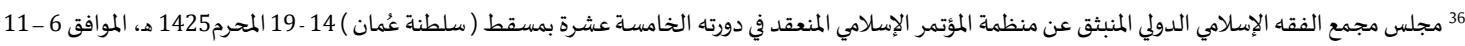

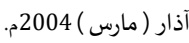

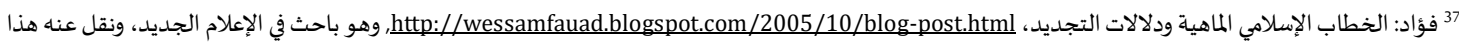
التعريف الدكتور عصام البشير في بحثة: "سمات الخطاب الإسلامي المعاصر". 
"المراعي لعلم المعاني" وهو العلم الذي يتناول الفصل والوصل، والحذف والتكرار في العبارات؛ كي تقون العبارات جزلة ومقنعة غير مملة ولا مخلة.

"ودلالات الألفاظ" وهو العلم الذي يتناول مباحث العموم والخصوص والتقييد والإطلاق، والإضمار والإجمال وغيرها.

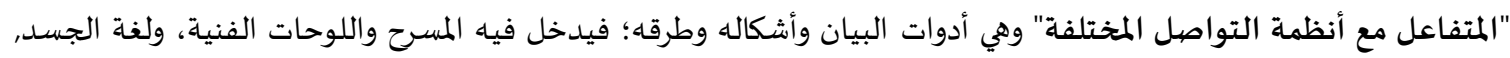
والإيحاءات وغيرها.

$$
\text { المطلب الثاني: أهمية الخطاب الإسلامي: }
$$

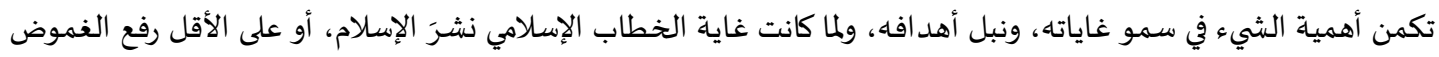

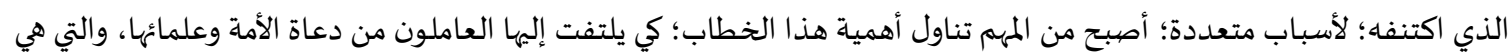
في ستة بنود على النحو التالي: أولاً: إنه وسيلة التواصل والاتصال بين المسلمين وغيرهم من البشر، فمن خلاله يتم رسم الإسلام بصورته الصحيحة، وعرض

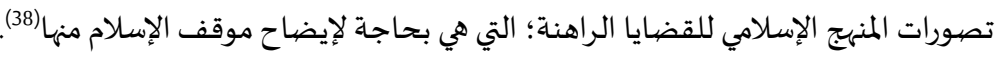
ثانياً: هو العامل الرئيس في تشكيل البنية الذهنية أو التكوين العقلي للمسلمين، فمن خلالهي يتم توجيه الأفراد وتغيير المجتمعات وإصلاح حال المسلمين واستئناف حضيارتهم (39).

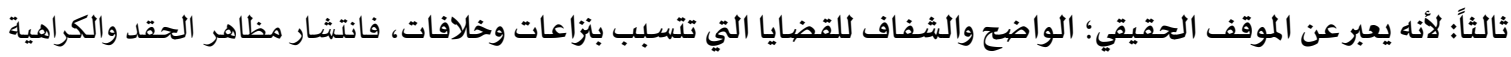
التي تحولت إلى سلوك عملي أدى لنزاعاتٍ وقلاقلَ بين الحضارة الإسلامية وغيرها من الحضارات؛ وظهور ما اصطلح عليه بلهيه بالإرهاب

الإسلامي، دفع الخطاب الإسلامي ليساهم في توضيح الرؤية وسبل الحل، وكيفية التعامل في هذه الظروف الريل الراهنة (40). رابعاً: ظهور خطاب يدعي انتماءه للإسلام، قد اعترته تشوهات عديدة, تسببت في إظهار صهورة سلبية عن الإسلام، خاصة فيما

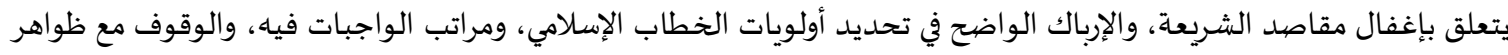
النصوص والجمود عند حرفيتها، والخلط في طبيعة العلاقة مع غير المسلمين، وهذا ما يوجب على علماء المسلمين الوسطيين إظهارَ الخطاب الإسلامي بشكله الصحيح (41).

خامساً: ظهورخطاب لا يقلٌ خطورة عن سابقه، وإن كان على طرف النقيض منه, وهو لا يلتزم بالثو ابت ومقاصيد الشريعة(42).

$$
\text { المبحث الثاني: إشكاليات الخطاب الإسلامي المعاصر }
$$

تَعْرِضُ للخطاب الإسلامي مجموعة من الإشكاليات والتحديات، وبما أن الخطاب الإسلامي يمثل ثروة اجتهادية في الحقل

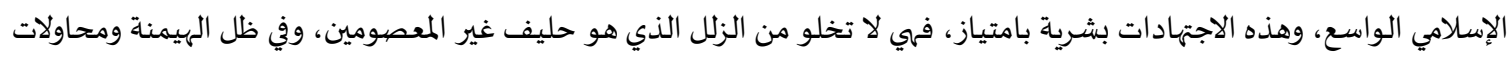
طمس كل ما هو إسلامي، نجد أن هناك مجموعة من التحديات والعراقيل التي توضع في طريق نهضية هذا الخطاب، تحول بينها وبين

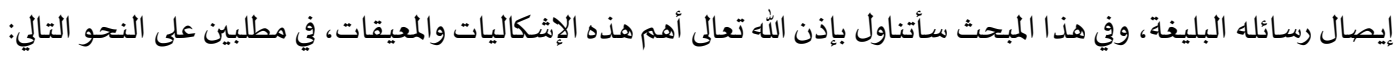
إن الخطاب الإسلامي له مكون رئيس، وهو المكون الشرعي أو الإلهي، ومكون آخر، وهو المكون البشري الذي يرتبط باجتهاديادات

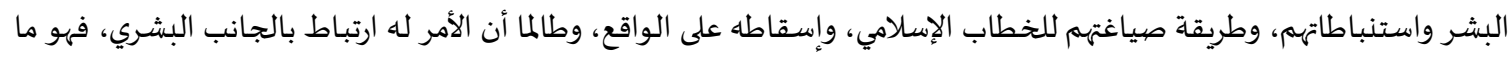
يعني إمكان الخطأ والزلل فيه، لذلك تَردِ على الخطاب الإسلامي بعض الإشكاليات، يمكن حصر أهمها في عشرة كما يلي: أولاً: محدودية الخطاب بحدود الدولة القطرية، وغياب مبدأ وحدة الأمة:

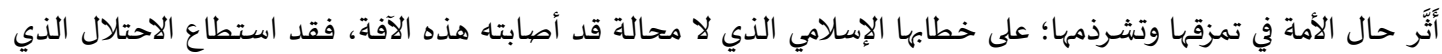

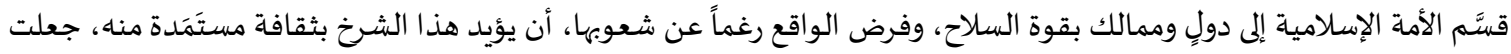
لنفسها موقعاً في قلوب الإسلاميين أنفسهم وهذا ما أثر على خطابها ومهابهم.

38 بوكروشة: الخطاب الإسلامي المعاصر المنهج والآليات، ص(171)، دعوة للتقويم وإعادة النظر, مؤسسة المنصور الثقافية: خصائص الخطاب الإسلامي المعاصر

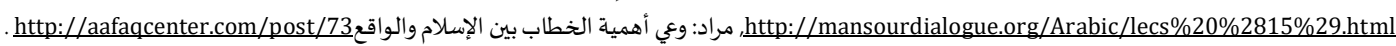

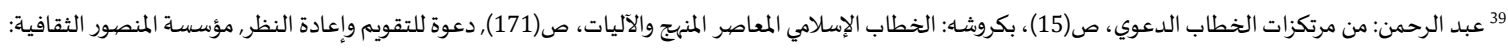

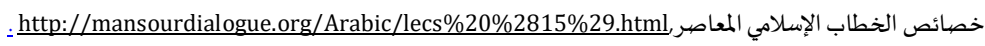

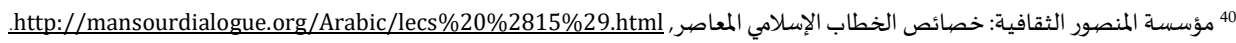

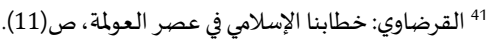
42 البنا: تجديد الخطاب الديني، ص(249). 
لذلك فمن الواجب أن يتنبه الخطاب الإسلامي إلى خطر تغلغل هذه الثقافة التي تمس مبداً عظيماً من مبادئ الإسلام وهو مبدأ

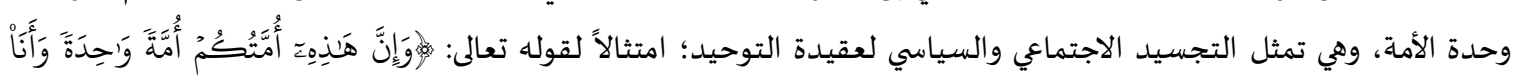

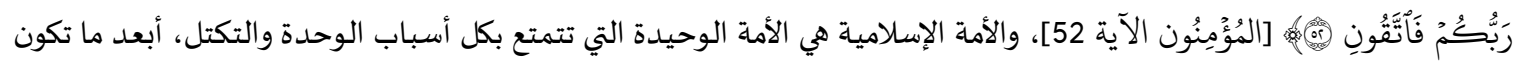
عن ذلك، وهو ما يعد تهديداً استراتيجياً للأمة (43).

ثانياً: التركيز على الجانب العقديّ في الإسلام، وإهمال مكوناته الاجتماعية والسياسية:

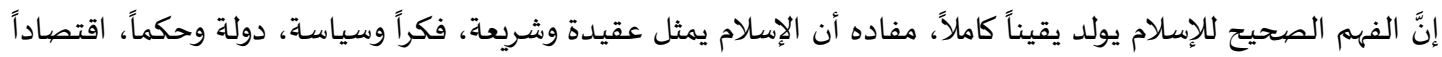

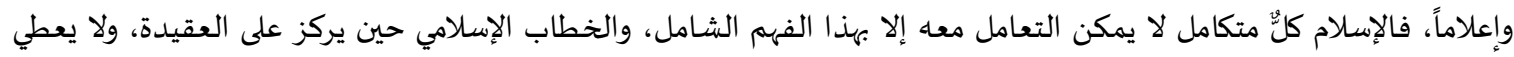
اهتماماً كاملاً بقيم هذه العقيدة وروحها الحية، من عدالة، وشورى، وحرية؛ وغيرها من المعاني السامية التي جاء الإسلام ليتممها

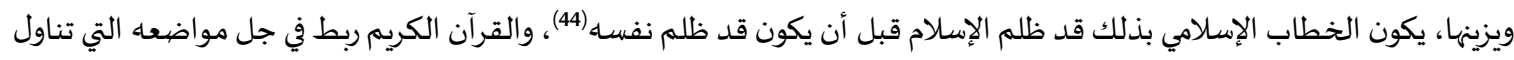

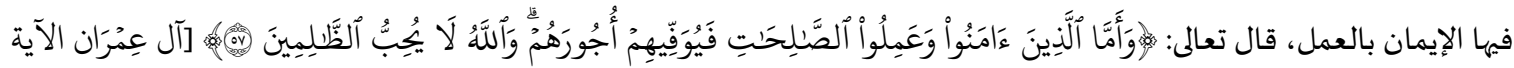

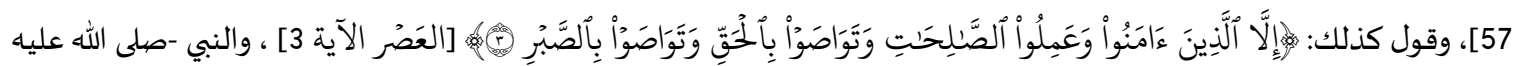

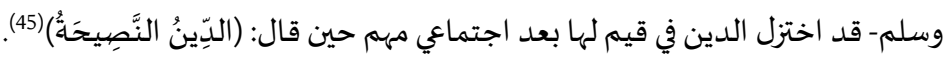
ثالثاً: عدم التفريق بين الخطاب الداخلي والخطاب الخارجي العام: إنَّ هذه الإشكالية يقع فيها صاحب الخبن الخطاب الإسلامي الذي لا يميز بين خطابه العام الذي يريد بها إيصال وجهاة النظر الإسلامية

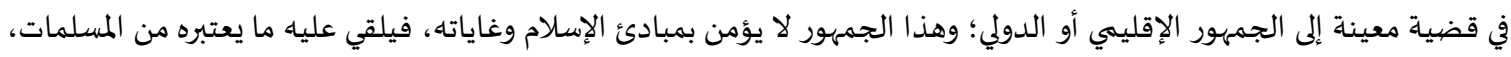

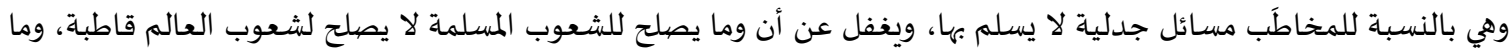

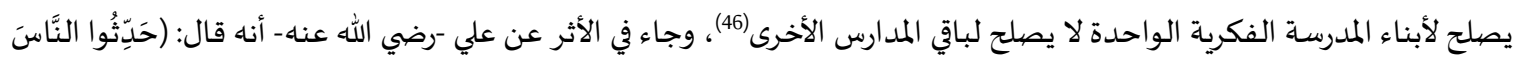

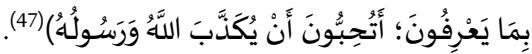
رابعاً: غلبة خطاب الزجروالعقاب، على الوعد والترغيب:

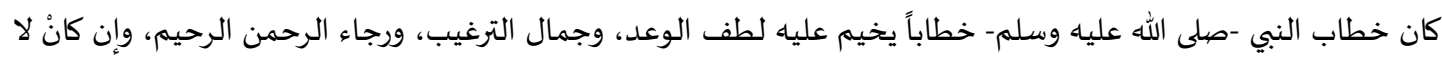

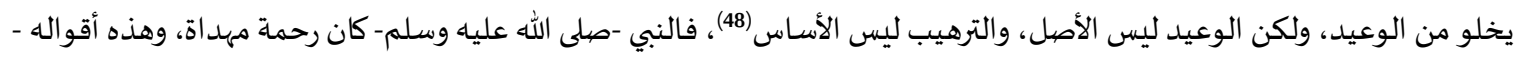

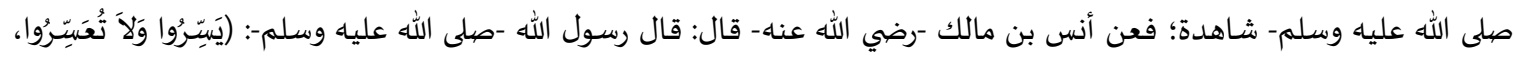

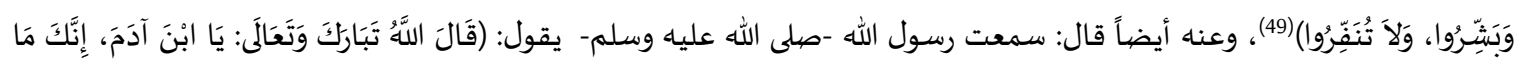

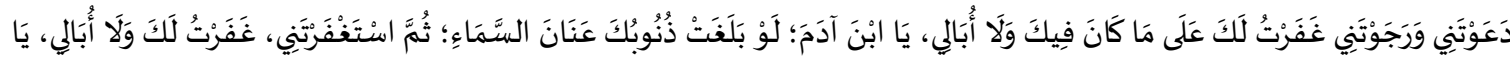

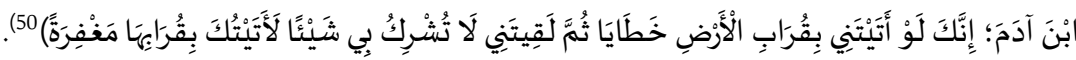

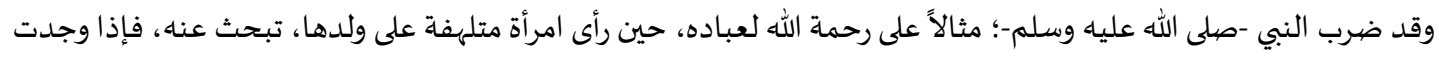

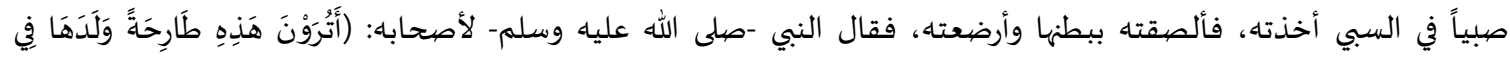

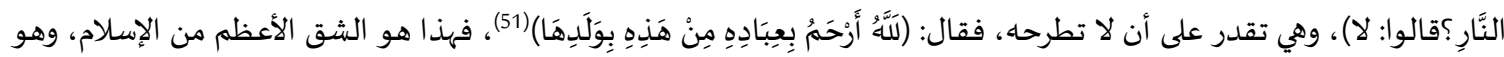

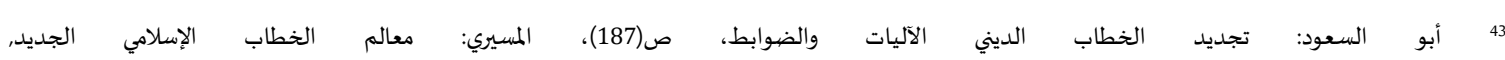
http://qassimy.com/vb/showthread.php?t=419577 http://www.aljazeera.net/pointofview/pages/1a88a5b1-1d44-426c-8980-da5765784cb5

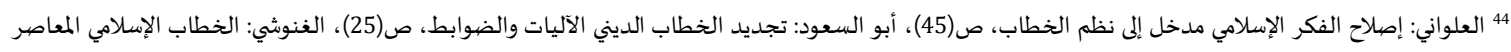

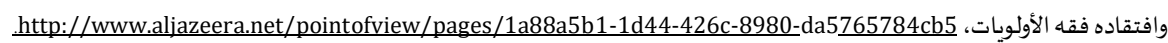

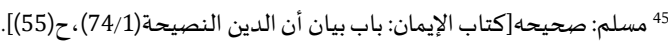

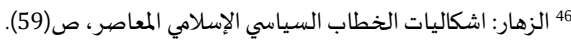

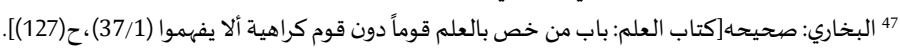

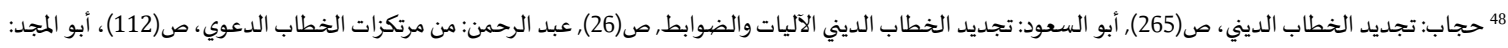

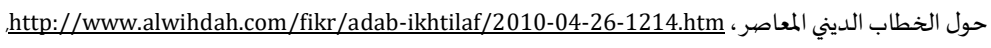

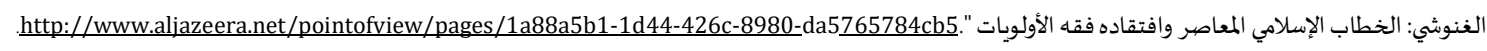

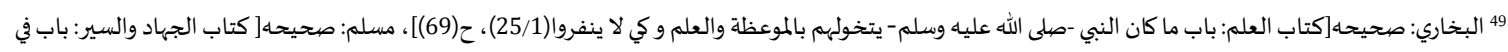

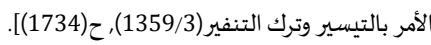

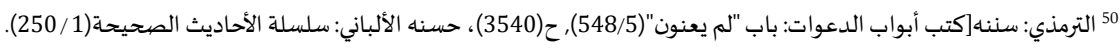

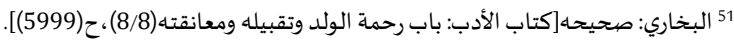




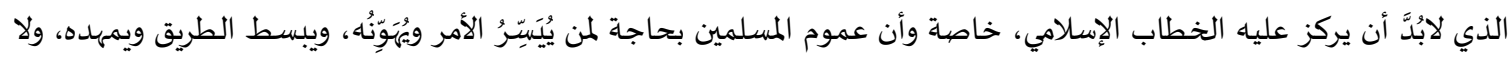
يعني ذلك غياب خطاب الترهيب مطلقاً (52). خامساً: إعطاء الأولوية للجزئيات والمظاهر، والغفلة عن الكليات والمقاصيد:

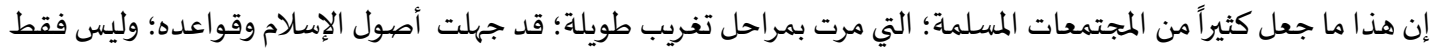

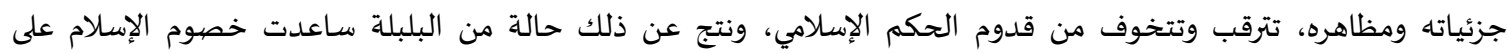

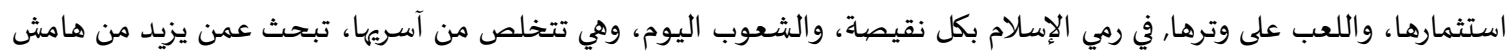

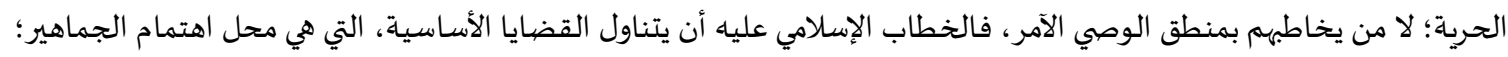

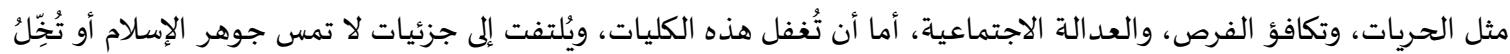

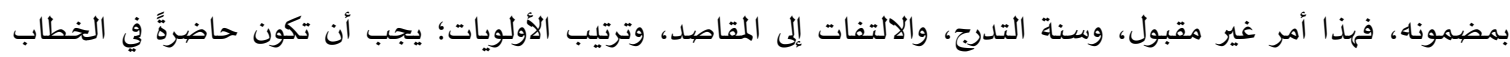

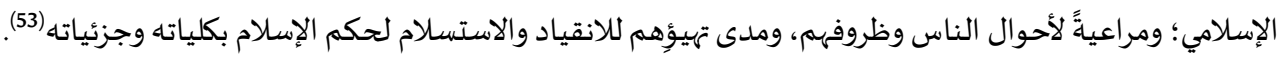

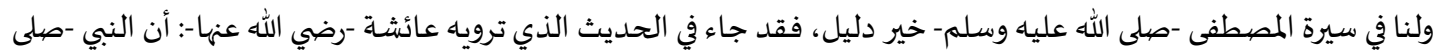

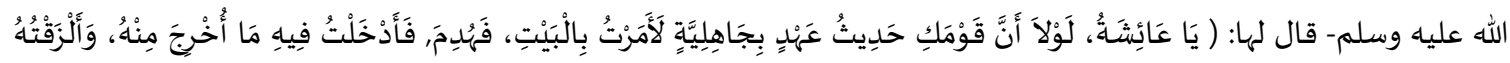

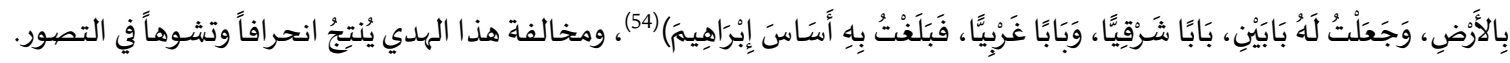

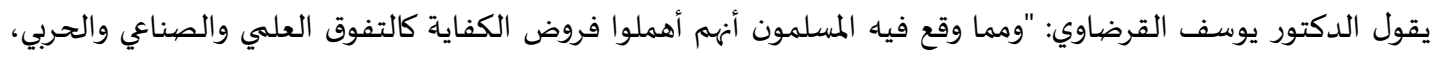

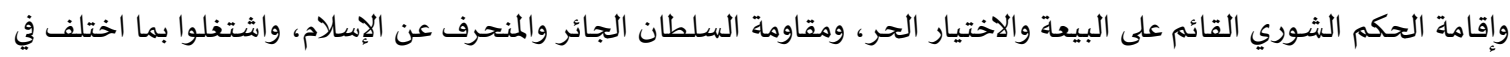

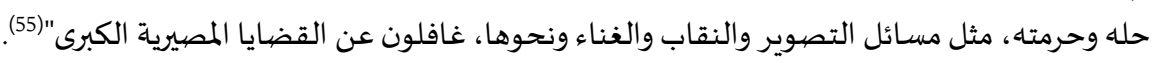

سادساً: الخلط بين العقيدة والفكر:

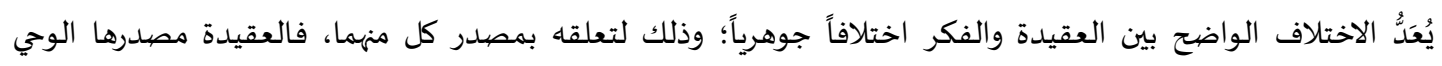

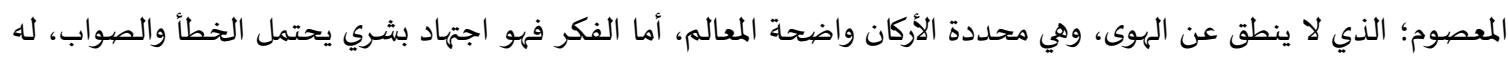

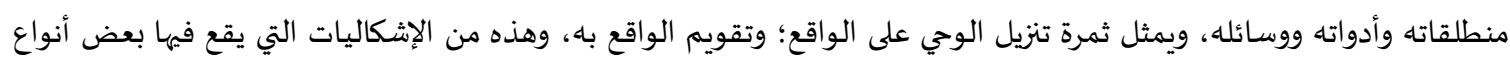

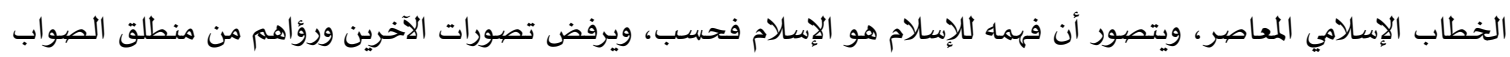
المطلق الذي يؤمن به (56). (الماهن.

سابعاً: مداومة الحديث عن الماضي، وثباته في وضعية المدافع:

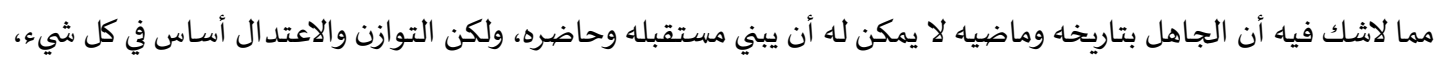

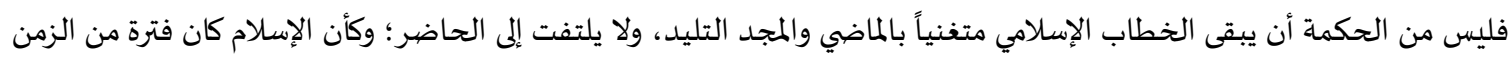

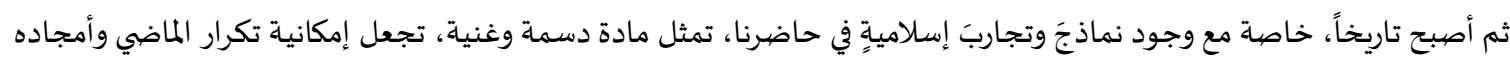

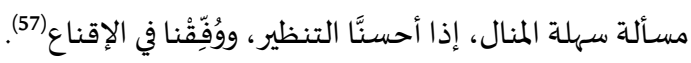

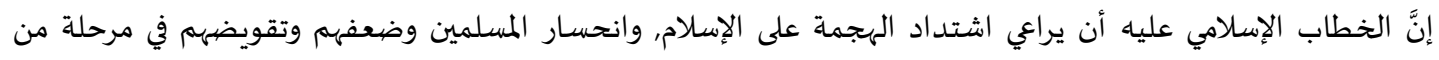

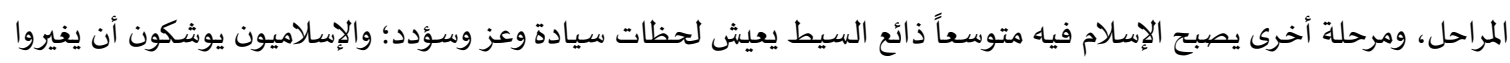
المعادلة الدولية ويقلبوا موازين العالم أم8رئ. ثامناً: الغفلة عن دور العقل، وأهمية العلم، في بناء التصهور الإسلامي:

(32 أربد الرحمن: من مرتكزات الخطاب الدعوي، ص(35).

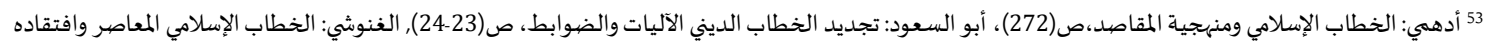

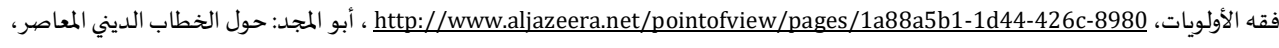
.http://www.alwihdah.com/fikr/adab-ikhtilaf/2010-04-26-1214.htm

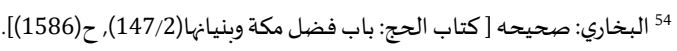

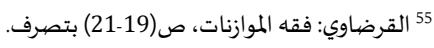

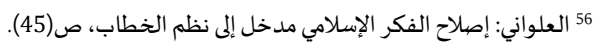

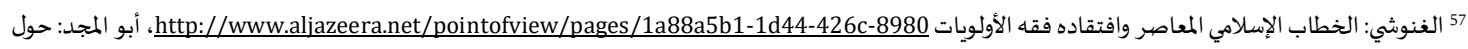

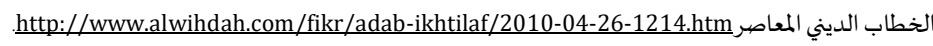
ئ الغنوشي: الخطاب الإسلامي المعاصر وافتقاده فقه الأولويات، 


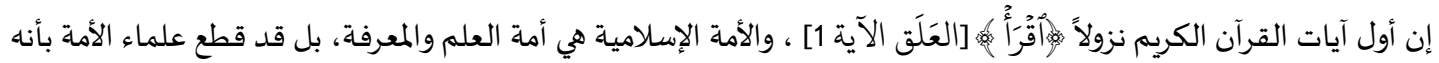

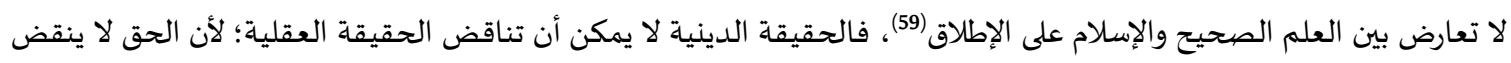

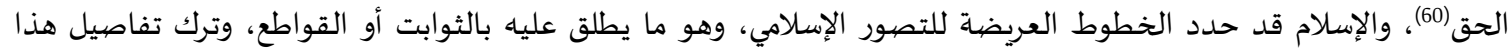

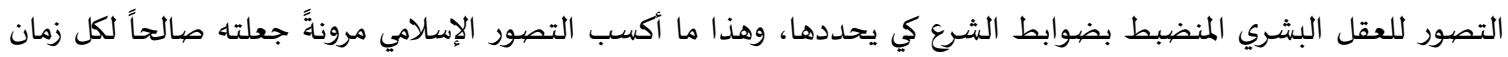

تاسعاً: عدم ضبط المصططلحات، و انسيابية المفاهيم:

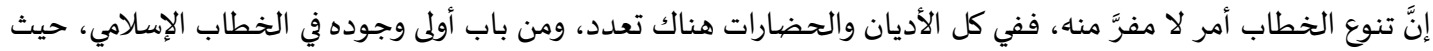

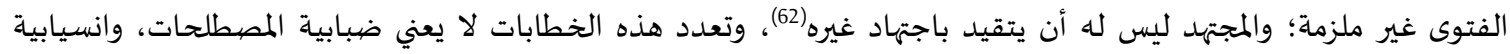

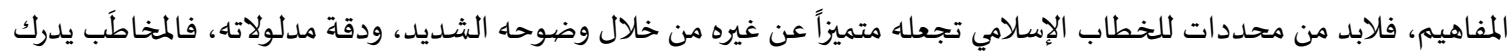

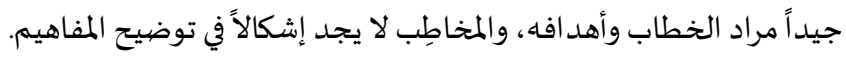

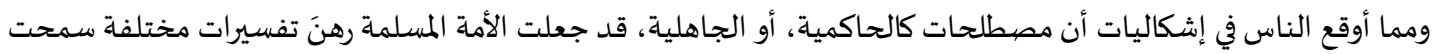

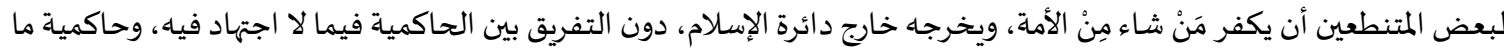

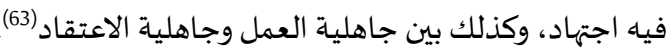

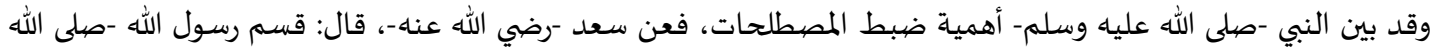

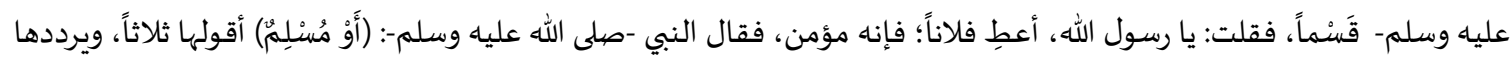

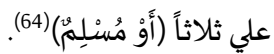

عاشراً: العداء الشديد للمخالف، ورفض التعدد الحضاري والثقافي:

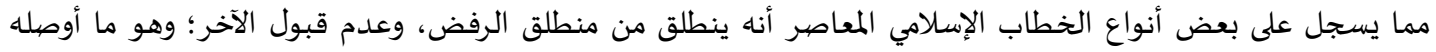

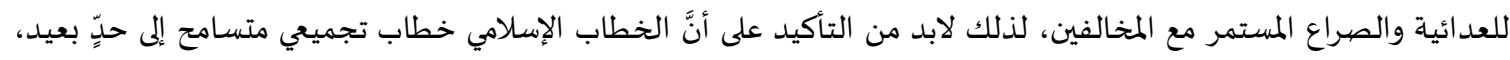

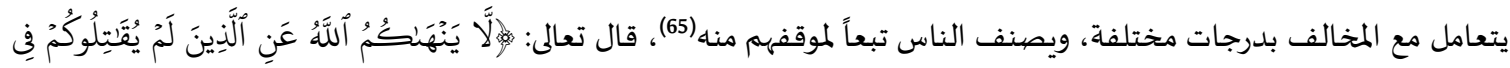

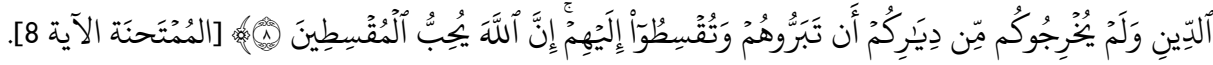

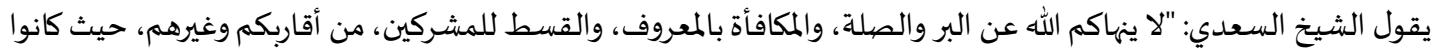

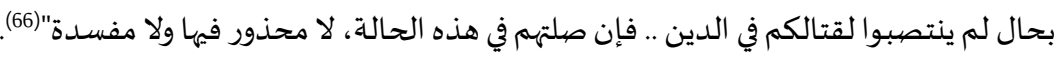

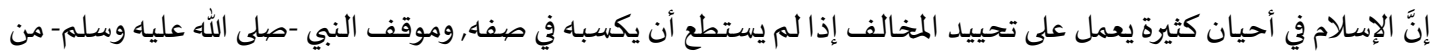

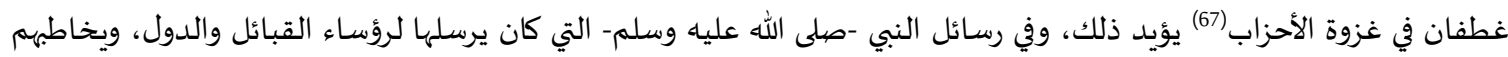

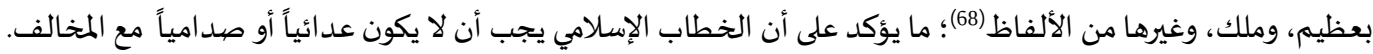

http://www.alwihdah.com/fikr/adab-ikhtilaf/2010 أبو السعود: تجديد الخطاب الديني الآليات والضوابط، ص(193)، أبو المجد: حول الخطاب الديني المعاصر، .04-26-1214.htm

60 القرضاوي: الرسول والعلم، ص(14).

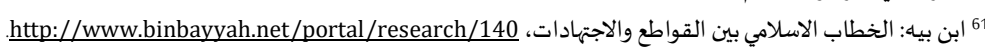

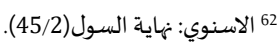

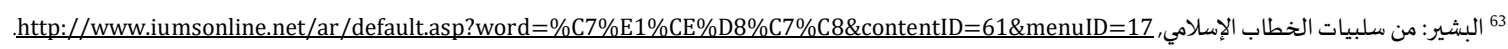

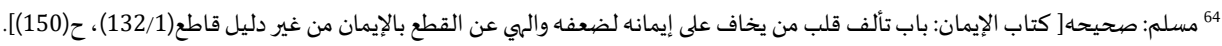

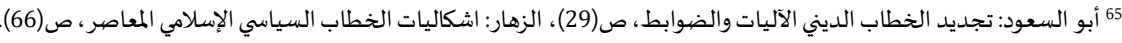

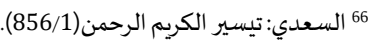
67 ابن حجر: فتح الباري(600/7) - (400). 68 حميد الله: مجموعة الوثائق السياسية للعهد النبوي والخلافة الراشدة، ص(100) وما بعدها. 
وتتضمن أهم النتائج والتوصيات وهي كما يلي:

هيمكن تعريف الخطاب الإسلامي بأنه: "البيانُ الواضحُ المبلغُ لمقصودِه، المفهُ للمخاطَبِ به، المرتكزُ على أصولِ النظرِ

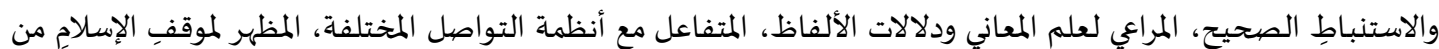

كل قضيةٍ تحتاج إلى بيان". • يعد الخطاب الإسلامي السبيلَ الوحيدَ لإعادة تكوين وتشكيل البنية الذهنية للمسلمين ولغيرهم، وعلى عاتقاه يقع واجب إظهار الوجاء الحقيقي للإسلام، وإعلاء قيماه ومشروعاء الحضاري. ظهرت خطابات تدعي انتمائها للإسلام وقد اعترتها تشوهات عديدة، وكانت لها صورة سلبية عن الإسلام من إغفال مقاصد الشريعة، والإبراك الواضح في تحديد أولويات الخطاب الإسلامي المعاصر. تعتري الخطاب الإسلامي مجموعة من الإشكاليات؛ تجعله مشوهاً أو منقوصاً، منها محدوديته، وبعده عن ترتيب أولوياته، وتعميم مصطلحاته، وتغييب العقل، واستعداء المخالفين. ثانياً: التوصيات:

يمكن للباحثين أن يقدما بعض التوصيات المتعلقة بالبحث, على النحو التالي: نوصي بتشكيل هيئة على غرار المجامع الفقهية، يكون دورها رسم معالم الخطاب الإسلامي، وبيان شكل الخطاب ومدى

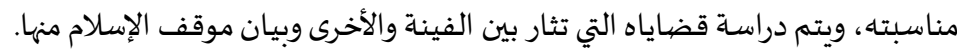
الاهتمام طلبة العلم والباحثين بقضايا الخطاب الإسلامي, وإجلاء موقف الإسلام منها بكل موضوعية وشفافية، على أن تتخلص

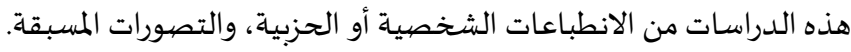
• عقد مؤتمرات علمية على المستويات المحلية, يتم خلالها تناول آخر القضيايا المحلية وبيان موقف الإسلام منها. تدشين مؤسسات إعلامية كون دورها نشر موقف الإسلام من القضايا والمشاكل المعاصرة، بحيث تستطيع هذه المؤسسات إيصال رسالة الإسلام إلى جميع أصقاع الأرض. نوصي بإعداد مادة علمية تدرس في الجامعات العربية والإسلامية تتناول خصيائص وضوابط الخطاب الإسلامي الوسطي، وتعرض موقف الإسلام من بعض القضيايا المعاصرة.

1. الآمدي، أبو الحسن سيد الدين علي بن أبي علي بن محمد بن سالم الثعلبي. الإحكام في أصهول الأحكام. المحقق: عبد الرزاق عفيفي، المكتب الإسلامي، بيروت- دمشق- لبنان. 2. الألوسي، شهاب الدين محمود بن عبد الله الحسيني. روح المعاني في تفسير القرآن العظيم والسبع المثاني. المحقق: علي عبد الباري عطية، دار الكتب العلمية- بيروت. 3. البخاري، محمد بن إسماعيل أبو عبدالله (1422ه). صحيح البخاري. المحقق: محمد زهير بن ناصر الناصر، دار طوق النجاة (مصورة عن السلطانية بإضافة ترقيم ترقيم محمد فؤاد عبد الباقي)، الطبعة الأولى.

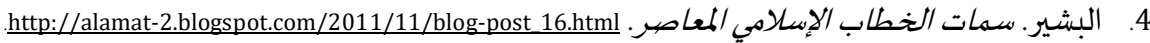
5. البصري، أبو الفداء إسماعيل بن عمر بن كثير القرشي (1419ه). تضسير القرآن العظيم. المحقق: محمد حسين شمس الدين, دار الكتب العلمية، منشورات محمد علي بيضون- بيروت، الطبعة الأولى. 6. البغدادي، أبو بكر أحمد بن علي بن ثابت بن أحمد بن مهدي الخطيب (1421ه). الفقيه والمتفقه. المحقق: أبو عبد الرحمن عادل بن يوسف الغرازي، دار ابن الجوزي- السعودية، الطبعة الثانية.

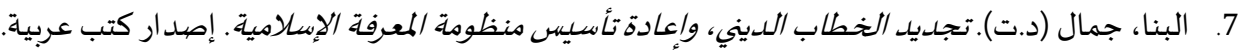
8. 9. الترمذي، أبو عيسى (1975). سنن الترمني. محمد بن عيسى بن سَوْرة بن موسى بن الضحاك، تحقيق وتعليق: أحمد محمد شاكر وآخرين، شركة مكتبة ومطبعة مصطفى البابي الحلبي- مصر، الطبعة الثانية. 
10. آل تيمية. المسيودة في أصهول الفقه. [بدأ بتصنيفها الجدّ: مجد الدين عبد السلام بن تيمية (ت: 652هـ)، وأضاف إليها الأب، عبد

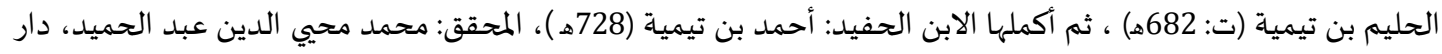

$$
\text { الكتاب العربي. }
$$

11. حجاب، محمد منير (2004). تجديد الخطاب الديني في ضوء الواقع المعاصر. دار الفجر للنشر والتوزيع، الطبعة الأولى.

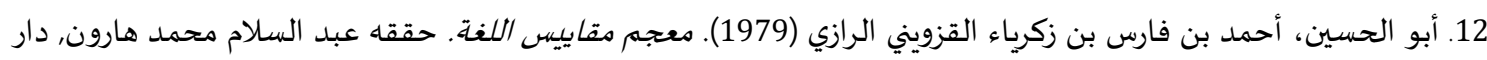
الفكر.

13. حميد الله، محمد (1987). مجموعة الوثائق السياسية للعهلد النبوي والخلافة الراشلدة. دار النفائس، الطبعة السادسة.

14. الحنفي، عبد العزيز بن أحمد بن محمد، علاء الدين البخاري. كشف الأسرار شرح أصبول البزدوي. دار الكتاب الإسلامي. 15. الرازي، فخر الدين أبو عبد الله محمد بن عمر بن الحسن بن الحسين التيمي الرازي (1997). المحصيول. دراسة وتحقيق:

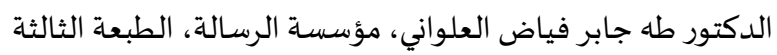
16. الزمخشري، أبو القاسم محمود بن عمرو بن أحمد، جار الله (1407ه). الكشاف عن حقائق غوامض التننيل. دار الكتاب مؤس العربي- بيروت، الطبعة الثالثة.

17. الزهار، محمود (1998). إشكاليات الخطاب السياسي الإسالامي المعاصرئ دار المستقبل، الطبعة الأولى.

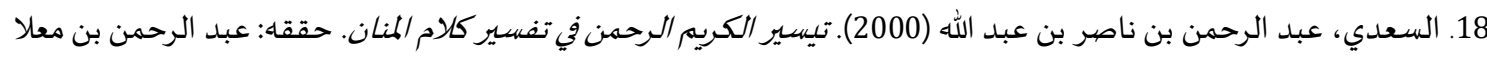
اللويحق، مؤسسة الرسالة، الطبعة الأولى. 19. أبو السعود، عبد رب النبي على. تجديد الخطاب الديني الآليات والضيوابط. ـ دار الكتب العليمة للنشر والتوزيع.

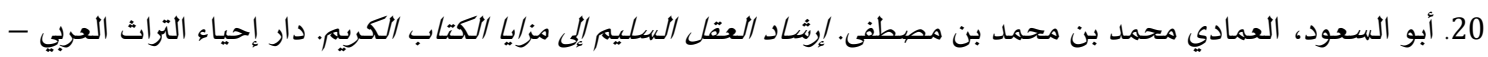
بيروت.

21. الشافعي، أحمد بن علي بن حجر أبو الفضل العسقلاني (1379ه). فتح الباري شرح صحيح البخاري. دار المعرفة-بيروت.

22. الشيرازي، أبو اسحاق إبراهيم بن علي بن يوسف (2003). اللمع في أصول الفقهـ. دار الكتب العلمياة، الطبعة الثانية.

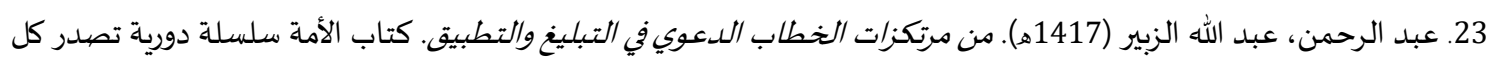

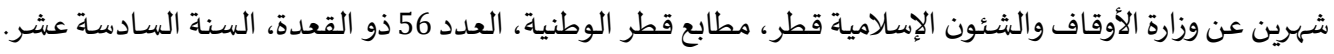

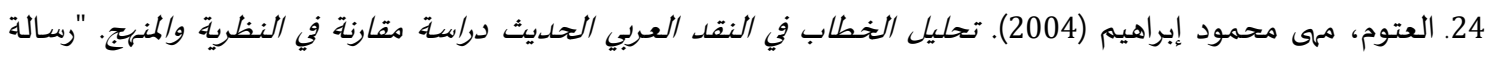
دكتوراة"، كلية الدراسـات العليا- الجامعة الأردنية. 25. العلواني، طه جابر (1995). إصلاح الفكر الإسلامي مدخل إلى نظم الخطاب في الفكر الإسلامي. طبعة منقحة ومزيد المعهد العالمي للفكر الإسلامي، مكتب الأردن.

26. علوش، سعيد (1985). معجم المصطلحات الأدبية المعاصرة. دار الكتاب اللبناني بيروت- لبنان، الطبعة الأولى.

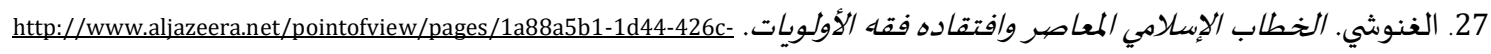
8980-da5765784cb5 28. أبو الفضل، محمد بن مكرم بن على (1414ه). لسان العرب. جمال الدين ابن منظور الأنصياري الرويفعى الإفريقى، دار صادربيروت، الطبعة الثالثة. 29. القرافي، أبو العباس شهاب الدين أحمد بن إدريس بن عبد الرحمن المالكي (1973). شرح تنقيح الفصول. المحقق: طه عبد الرؤوف سعد، شركة الطباعة الفنية المتحدة، الطبعة الأولى. 30. القرضاوي، يوسف (1984). الرسول والعلم. مؤسسة الرسالة للطباعة والنشر والتوزيع، الطبعة الأولى. 31. القرضاوي، يوسف (2004). خطابنا الإسلامي في عصبر العولمة. دار الشروق، الطبعة الأولى. 32. الماوردي، أبو الحسن علي بن محمد بن محمد بن حبيب البصري البغدادي. النكت والعيون. حققه السيد ابن عبد المقصود بن عبد الرحيم، دار الكتب العلمياة - بيروت / لبنان. 33. مؤسسة المنصور الثقافية. خصائص الخطاب الإسلامي المعاصر، 34. 34. أبو المجد. الخطاب الديني /لمعاصر. 3وttp://www.alwihdah.com/fikr/adab-ikhtilaf/2010-04-26-1214.htm 35. مجمع اللغة العربية بالقاهرة. المعتم الوسيط. (إبراهيم مصطفى / أحمد الزيات / حامد عبد القادر / محمد النجار)، دار الدعوة. 36 
37. المرسي، أبو الحسن علي بن إسماعيل بن سيده. المحكمر والمحيط الأعظم.

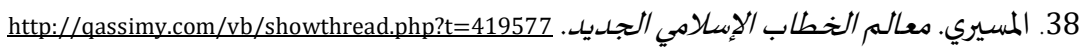

39. أبو المعالي، عبد الملك بن عبد الله بن يوسف بن محكمد الجويني (1997). البرهان في أصهول الفقه. ركن الدين، المحقق: صلاح بن

محمد بن عويضة، دار الكتب العلمية بيروت - لبنان، الطبعة الأولى.

40. منتدى اللسانيات: مفهوم الخطاب في الدراسات اللغوية والنقدية.

41. نواري، بالة (2008). أدبية الخطاب النثري عند القاضي عياض.

42. النيسابوري، مسلم بن الحجاج أبو الحسن القشيري. صحيح مسلهم. المحقق: محمد فؤاد عبد الباقي، دار إحياء التراث العربي -

بيروت.

43. اليمني، محمد بن علي بن محمد بن عبد الله الشوكاني (1999). إرشاد الفحول إلى تحقيق الحق من علم الأصهول. المحقق: الشيخ

أحمد عزو عناية، دمشق - كفر بطنا، دار الكتاب العربي، الطبعة الأولى. 
المجلة الدولية للدراسـات الإسلامية المتخصصية

International Journal of Specialized Islamic Studies (SIS)

www.refaad.com

Journal Homepage: https://www.refaad.com/views/SIS/Home.aspx

ISSN: 2617-6246(Online) 2617-6238(Print)

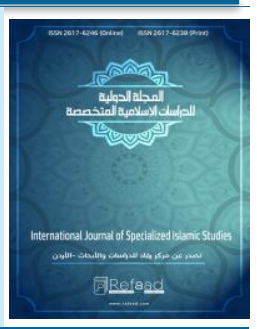

\title{
The problems of contemporary Islamic discourse
}

\author{
Rafeeq Asaad Radwan \\ Assistant Professor of Comparative Jurisprudence at the University of Gaza, Palestine \\ rradwan@iugaza.edu.ps
}

Abdul Karim Rabah Miqdad

$\mathrm{PhD}$ in Comparative Jurisprudence from Al-Zaytoonah University, Palestine

Received: 21/9/2021 Revised: 30/9/2021 Accepted: 3/11/2021 DOI: https://doi.org/10.31559/SIS2021.6.3.1

Abstract: Islamic Sharia is the conclusion of the messages. It is valid for every time and place. It is able to answer and clarify the provisions of every issue and event. It revealed the reality of the Islamic discourse and its importance; then addressed the problems of contemporary Islamic jurisprudence and ended with a conclusion in which the most important findings and recommendations.

Keywords: discourse; Islamic; problems; contemporary.

\section{References:}

1. 'bd Alrhmn, 'bd Allh Alzbyr (1417h). Mn Mrtkzat Alkhtab Ald'wy Fy Altblygh Walttbyq. Ktab Alamh Slslh Dwryh Tsdr Kl Shhryn 'n Wzarh Alawqaf Walsh'wn Aleslamyh Qtr, Mtab' Qtr Alwtnyh, Al'dd 56 Dw Alq'dh, Alsnh Alsadsh 'shr.

2. Al'lwany, Th Jabr (1995). Eslah Alfkr Aleslamy Mdkhl Ela Nzm Alkhtab Fy Alfkr Aleslamy. Tb'h Mnqhh Wmzyd Alm'hd Al'almy Llfkr Aleslamy, Mktb Alardn.

3. 'lwsh, S'yd (1985). M'jm Almstlhat Aladbyh Alm'asrh. Dar Alktab Allbnany Byrwt- Lbnan, Altb'h Alawla.

4. Al'twm, Mha Mhmwd Ebrahym (2004). Thlyl Alkhtab Fy Alnqd Al'rby Alhdyth Drash Mqarnh Fy Alnzryh Walmnhj. "Rsalt Dktwrah",Klyt Aldrasat Al'lya- Aljam'h Alardnyh.

5. Alamdy, Abw Alhsn Syd Aldyn 'ly Bn Aby 'ly Bn Mhmd Bn Salm Alth'lby. Alehkam Fy Aswl Alahkam. Almhqq: 'bd Alrzaq 'fyfy, Almktb Aleslamy, Byrwt- Dmshq- Lbnan.

6. Alalwsy, Shhab Aldyn Mhmwd Bn 'bd Allh Alhsyny. Rwh Alm'any Fy Tfsyr Alqran Al'zym Walsb' Almthany. Almhqq: 'ly 'bd Albary 'tyh, Dar Alktb Al'lmyh- Byrwt.

7. Albghdady, Abw Bkr Ahmd Bn 'y Bn Thabt Bn Ahmd Bn Mhdy Alkhtyb (1421h). Alfqyh Walmtfqh. Almhqq: Abw 'bd Alrhmn 'adl Bn Ywsf Alghrazy, Dar Abn Aljwzy- Als'wdyh, Altb'h Althanyh.

8. Albkhary, Mhmd Bn Esma'yl Abw 'bdallh (1422h). Shyh Albkhary. Almhqq: Mhmd Zhyr Bn Nasr Alnasr, Dar Twq Alnjah (Mswrh 'n Alsltanyh Bedafh Trqym Trqym Mhmd F'ad 'bd Albaqy), Altb'h Alawla.

9. Albna, Jmal (D.T). Tjdyd Alkhtab Aldyny, We'adh Tasys Mnzwmh Alm'rfh Aleslamyh. Esdar Ktb 'rbyh.

10. Albshyr. Smat Alkhtab Aleslamy Alm'asr. http://alamat-2.blogspot.com/2011/11/blog-post 16.html.

11. Albsry, Abw Alfda' Esma'yl Bn 'mr Bn Kthyr Alqrshy (1419h). Tfsyr Alqran Al'zym. Almhqq: Mhmd Hsyn Shms Aldyn, Dar Alktb Al'Imyh, Mnshwrat Mhmd 'ly Bydwn- Byrwt, Altb'h Alawla.

12. Abn Byh. Alqwat' Walajthadat Fy Alkhtab Aleslamy. http://www.binbayyah.net/portal/research/140.

13. Abw Alfdl, Mhmd Bn Mkrm Bn 'la (1414h). Lsan Al'rb. Jmal Aldyn Abn Mnzwr Alansary Alrwyf'a Alefryqa, Dar Sadr- Byrwt, Altb'h Althalthh.

14. Alghnwshy. Alkhtab Aleslamy Alm'easr Waftqadh Fqh Alawlwyat. http://www.aljazeera.net/pointofview/pages/1a88a5b1-1d44-426c-8980-da5765784cb5 
15. Hjab, Mhmd Mnyr (2004). Tjdyd Alkhtab Aldyny Fy Dw' Alwaq' Alm'asr. Dar Alfjr Llnshr Waltwzy', Altb'h Alawla.

16. Hmyd Allh, Mhmd (1987). Mjmw't Alwtha'q Alsyasyh Ll'hd Alnbwy Walkhlafh Alrashdh. Dar Alnfa's, Altb'h Alsadsh.

17. Alhnfy, 'bd Al'zyz Bn Ahmd Bn Mhmd, 'la' Aldyn Albkhary. Kshf Alasrar Shrh Aswl Albzdwy. Dar Alktab Aleslamy.

18. Abw Alhsyn, Ahmd Bn Fars Bn Zkrya' Alqzwyny Alrazy (1979). M'ejm Mqayys Allghh. Hqqh 'bd Alslam Mhmd Harwn, Dar Alfkr.

19. Alqrafy, Abw Al'bas Shhab Aldyn Ahmd Bn Edrys Bn 'bd Alrhmn Almalky (1973). Shrh Tnqyh Alfswl. Almhqq: Th 'bd Alr'wf S'd, Shrkt Altba'h Alfnyh Almthdh, Altb'h Alawla.

20. Alqrdawy, Ywsf (1984). Alrswl Wal'lm. M'sst Alrsalh Lltba'h Walnshr Waltwzy', Altb'h Alawla.

21. Alrazy, Fkhr Aldyn Abw 'bd Allh Mhmd Bn 'mr Bn Alhsn Bn Alhsyn Altymy Alrazy (1997). Almhswl. Drash Wthqyq: Aldktwr Th Jabr Fyad Al'lwany, M'sst Alrsalh, Altb'h Althalthh.

22. Als'dy, 'bd Alrhmn Bn Nasr Bn 'bd Allh (2000). Tysyr Alkrym Alrhmn Fy Tfsyr Klam Almnan. Hqqh: 'bd Alrhmn Bn M'la Allwyhq, M'sst Alrsalh, Altb'eh Alawla.

23. Abw Als'wd, 'bd Rb Alnby 'Ela. Tjdyd Alkhtab Aldyny Alalyat Waldwabt. Dar Alktb Al'lymh Llnshr Waltwzy'.

24. Abw Als'wd, Al'mady Mhmd Bn Mhmd Bn Mstfa. Ershad Al'ql Alslym Ela Mzaya Alktab Alkrym. Dar Ehya' Altrath Al'rby - Byrwt.

25. Alshaf'y, Ahmd Bn 'ly Bn Hjr Abw Alfdl Al'sqlany (1379h). Fth Albary Shrh Shyh Albkhary. Dar Alm'rfhByrwt.

26. Alshyrazy, Abw Ashaq Ebrahym Bn 'ly Bn Ywsf (2003). Allm' Fy Aswl Alfqh. Dar Alktb Al'lmyh, Altb'h Althanyh.

27. Altrmdy, Abw 'ysa (1975). Snn Altrmdy. Mhmd Bn 'ysa Bn Swrirh Bn Mwsa Bn Aldhak, Thqyq Wt'lyq: Ahmd Mhmd Shakr Wakhryn, Shrkt Mktbt Wmtb'h Mstfa Albaby Alhlby- Msr, Altb'h Althanyh.

28. Al Tymyh. Almswdh Fy Aswl Alfqh. [Bda Btsnyfha Aljd: Mjd Aldyn 'bd Alslam Bn Tymyh (T: 652h), Wadaf Elyha Alab, 'bd Alhlym Bn Tymyh (T: 682h), Thm Akmlha Alabn Alhfyd: Ahmd Bn Tymyh (728h), Almhqq: Mhmd Mhyy Aldyn 'bd Alhmyd, Dar Alktab Al'rby.

29. Alzmkhshry, Abw Alqasm Mhmwd Bn 'mrw Bn Ahmd, Jar Allh (1407h). Alkshaf 'n Hqa'q Ghwamd Altnzyl. Dar Alktab Al'rby- Byrwt, Altb'h Althalthh.

30. Alzhar, Mhmwd (1998). Eshkalyat Alkhtab Alsyasy Aleslamy Alm'asr. Dar Almstqbl, Altb'h Alawla. 